\title{
Implementation and Effectiveness of New Technologies in Housekeeping Department
}

\author{
Parikshit Das 1 \\ ${ }^{1}$ Asst. Professor, School of Hotel Management \& Tourism, Lovely professional University, Punjab, India
}

\begin{abstract}
When everything from front workplace to food and liquid has started the new technology within the same time work department additionally go with new technology they must not be in the age. In nowadays in building and hospital or any tourist sector work can not be outlined as cleanup and maintaining totally different surfaces there's a such a lot issue on the far side that additionally. currently days every and each trade is functioning through a technology-driven transformation and there's no totally different in cordial reception industry additionally. In these topics we tend to are planning to highlights the present challenges that we face from the worker and therefore the best practices on new technologies which may be innovated for the building trade, and if it goes well then we are able to apply this new technologies effectively within the building in work department. it's the upper growth and the and therefore the and additionally the cut tools for the building and hospital trade also. These articles delineated the teachers and up to date building work technologies effectiveness. This new technological innovation within the work service is made public on very cheap of the model guest cycle. fine quality technological service is that the pillar of the work department it will create the work easier. building work have to be compelled to be a IT savvy housekeeping, cross coaching for the worker, $\mathrm{TV}$, radio lightweight curtain area service laundry assortment every and each issue that is an element of the work are going to be controlled from one device. If these all are often implementing in a very systematic manner within the cordial reception trade then it will cause be an enormous opportunities and future profit for the hospital industry.
\end{abstract}

\section{Keywords}

Housekeeping, New technologies, Hospitality industry, Hotel

Article Received: 10 August 2020, Revised: 25 October 2020, Accepted: 18 November 2020

\section{Introduction}

In order to enhance the work service and to extend the standard of the housekeeping service we'd like to pioneer the new technology within the welcome trade. the method of the truth and therefore the implementation is intense. within the same page, guests are mistreatment this technology in one building conjointly the same time it's increasing the demand of the new technology also within the house keeping department in alternative hotels. Technology also can represented as modification, making, and usage of recent tools, techniques, and technique of organization so as to create the life a lot of easier. Through the new technologies guest will book the space ,can decision the space attendant for the service and may management the sunshine operate the curtain every and each factor will be done from one device.

Technological innovation is known wide currently days within the building trade and hospital industry additionally in the terms of work department. it'll prove that new technology within the work department will increase the standard and standard of the work and same time block the price and increase the value of the department additionally. New technologies within the work department will build the heap of changes once the guest will going the keep in the building and it'll increase the demand additionally in the hotel trade.

once implementation and innovation of the new technologies within the work department all the worker of the building and therefore the same time the guest is additionally going the face the heap of downside however we've got the overcome those problem by giving the right coaching to the employee and educate the guest regarding the technology . so as to beat the all difficulties we've got to review on numerous influences and that we ought to take the feedback additionally from the guest.

The motive for the publication is from the bottom level we've got the valuate the new technologies and that we got to understand the effectiveness once the implementation of the new technology within the work department in the building and therefore the hospital trade on the worker and the guest. 


\section{IT Savvy Housekeeping}

Most of the hotels presently days throughout the world endued with heap of money therefore on boost the new technologies in work department. building or welcome business endued with on knowledge technology to induce new work surroundings among the work department. New technologies like Wi-Fi (wire less fidelity ), frequency identification, computing, self service, voice internet protocol, so on .Many types of code is made-up among the work department with facilitate of technology and so the the consumer involvement conjointly exaggerated in service delivery.

Once means back, hotels, motels and various welcome businesses occupied a fairly straightforward space in people's live, they were a section for guests to induce their heads aloof from home. but anyone who's spent time within the welcome business within the last a few years is conscious of that the role of technology in cordial reception businesses has drastically distended .

In many cases, they're turning into hub of action unto themselves. Most of this activity depends straight or indirectly on technology, making IT extra important to building operations and so the visitor knowledge than ever before.

so on the concept of my experience and studies, i'm about to share variety of the best and so the the most recent technologies that building business is exploitation to ease their work and conjointly for the comfort of the guest.

\section{Artificial Intelligence :}

Having associate degree intelligent building that surpass shopper opportunity is that the plan many stylish welcome leaders and repair partner conjure. What adds viability to the current construct is that the thought of constructing it all multiplied with AI-powered care, support and services. There are positive essential components that make hotels intelligent. variety of that are, Digital facilitate, Voice-activated services, Travel experience enhancers ,mechanical process (mechanism knowledge).one amongst the terribly advanced among of these is voice activated services . during this a AI is put in within the rooms of the building a bit like SIRI or ALEXA . once guest enters within the room it'll be settled up by the building person consistent with the guest and once this it greets the guest whenever he enters the area and he will order something by simply merely ordering to the room AI, and can also management the area $\mathrm{AC}$ temperature and it also can perform such a big amount of different tasks like setting alarm, demand area improvement, demand laundry, and so on .

\section{Self Service :}

Self-Service Technologies are technological interfaces permitting customers to provide services freelance of involvement of direct service worker. Self-Service technologies are commutation several face-to-face service interactions with the intention to create service transactions additional correct, convenient and quicker. Customers need their issues resolved promptly and feel that finding out the solution themselves is faster than contacting the corporate. what is more, self-service improves client data, because it permits them to resolve issues at their speed and learn the maximum amount or as very little as they require. 


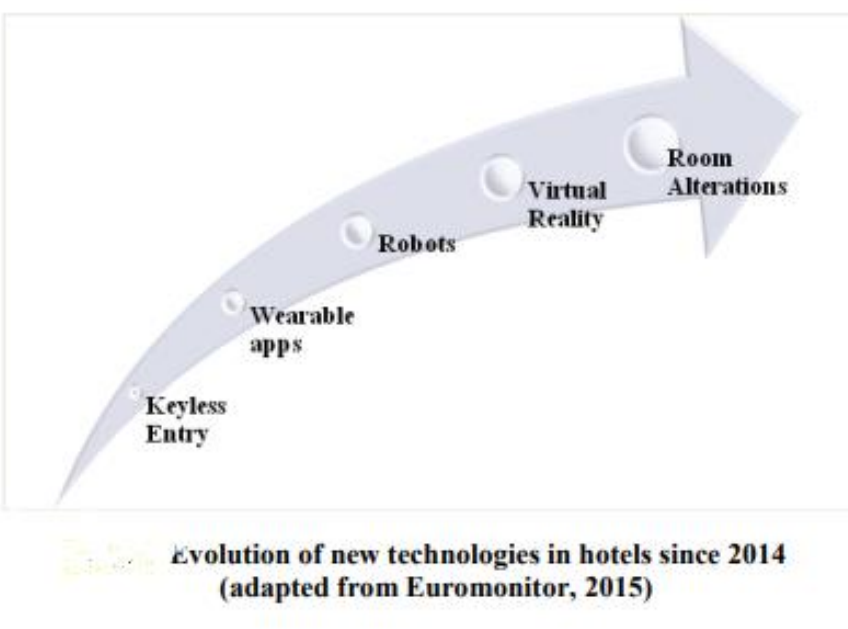

\section{Check-In Gadgets:}

Hotels that are technically not that advanced are making an attempt to ease down the arrival method in their building. what happen at a building throughout peak seasons, guests comes in teams and also the hotels are on 100 percent occupancies . therefore at that point guests got to wait long for his or her communicate visit reception . it feels terribly unhealthy to not be able to offer smart welcome to the guests therefore to ignore this example hotels currently mistreatment sensible gadgets to form check ins simple and trouble free . some hotels as an example Hyatt andaz aerocity New Delhi doesn't have reception . they are doing sign on on tablets in guest rooms . several different gadgets like sensible scanners are wide used currently on a daily basis, as an example the oberoi gurugram uses the sensible scanners to scan guest's documents like passport, aadhar card, pan card etc, what it do is it doesn't take time we tend to simply got to roll it on the surface of the document and it'll save the scanned image of the document within the system mechanically . with these kind of gadgets, cluster check ins are currently terribly simple to perform additionally it makes guest very comfy to deal .

\section{Screen Time :}

Few years back New Castle's Halifax property, the Westin star Scotian, started a system that has housework employees hand-held device joined with the facility's PMS. This device provides real time information to the housework department through the system additionally the same time guest also get the update concerning the area standing.

For a example at the time of self sign in once the guest can do the check in through the mobile app identical info will reaching to be send to the housework department additionally via system and consistent with that house servant will begin getting ready the area for the guest arrival.

\section{Employee Training:}

Hospitality trade has a lot of turnover close to concerning thirty per cent for the non organization position. revenue is extremely pricey therefore so as to avoid this value we'd like constant worker additionally the coaching also. For a example Novility offers the LIVE coaching system, that worker a mix of motion pursuit and speech recognition technology to make coaching modules for the workers that cowl everything from normal procedure for space attendants, to biotechnology stretchs geared toward reducing injuries and 
language talent that facilitate staff develop vocabulary round the key areas.

consistent with Novility, the system's advantages embrace injury bar, reduced shadowing time and reduced coaching prices, still as multiplied cleanliness ratings, higher review scores and better worker retention.

Improved the space attendant productivity up to twenty

we have a tendency to are ready to minimize the time for the ground supervisor up to fourhundredth

scale back eightieth telephone call between front workplace and work.

Workload properly distributed with within the space attendant.

Able to deliver the moment info with within the work workers.

We can check the 64000 time standing of the space in terms of sign up scrutinize.

\section{Optii Keeper:}

The typical work day starts with a gaggle of individuals gathering in properties basement manufacturing schedules of rooms, printing out all those papers and golf stroke them on clipboards. (It's gotten slightly higher as a result of as individuals begin going with some technology, they're a minimum of golf stroke it on devices). Either way, it's a vast series of events and by the time they've got the schedules prepped and written - be it for no matter reason, they're usually already obsolete. Then you hand the clipboards to the team, they get their keys and their off. They're unbound, no one is aware of wherever they're. Designed by trade insiders, Optii mechanically estimates cleanup times by examining guest kind and use-pattern to then faithfully predict, manage and optimize your work schedules in period.
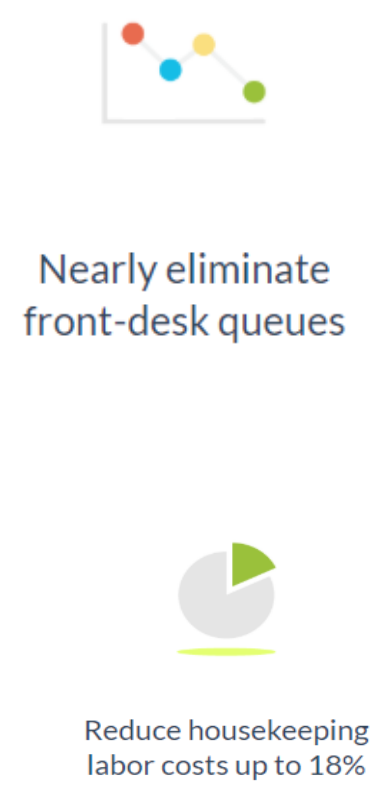

Significantly improve online guest reviews

Increase productivity up to $24 \%$

\section{The Robot Cleaner:}

Austin, Texas-based Maidbot has developed Associate in Nursing autonomous hotel-cleaning answer nicknamed "Rosie."

Kailah Rockwood, Maidbot's director of worldwide management, says the push-and-pull motions of vacuuming are a number one contributor to the repetitive-motion injury suffered by housekeepers.

"It's disposing of from a secular task that may leave [housekeepers] symptom physically," explains Rockwood. "Vacuuming is one in every of the most important [sources] of workers'-comp complaints within the welcome trade.'Designed to be transported on a work cart, every "Rosie" unit weighs nine lbs. additionally to autonomous operation, every unit collects information, together with however long it takes to scrub an area, and may discover would-be maintenance problems like the presence of wetness within the carpet.

\section{Effect on Housekeeping Service through Technology:}

Technology can also be used as a creating,modulation,usage and data of tools, machines ,technique, craft system and ways of organization so as to unravel a drag. Technology will build the changes within the human resources additionally the same time on the various section of housework department also. 
Housekeeping is that the act of cleanup the rooms and therefore the furnishing of rooms. several duties enclosed within the term housework operations are, however not restricted :

-Disposing of rubbish

- dynamical and laundry linen

-Cleaning dirty expanse

-Dusting and vacuuming

-Removing leaves from rain gutters

-Washing windows and sweeping doormats

Not solely these by the new technologies we are able to keep the record of the guest history. the main points of the guest that we tend to are keeping with United States of America which will facilitate us to boost the selling strategy conjointly.

In this era, we tend to see however effective the advancement of technology is, that it's capable of satisfying the requirements of the guests within the field of welcome. These info ANd communication technologies are helpful to an extent that it's exaggerated potency of daily work. we tend to might conjointly decision it as computer science, since these knowledgeable systems prepare the building reports and ease the flow of documentation with within the hotel.

These systematic procedures have exaggerated the productivity of the trade as a result of it's capable of distinguishing and detection the faults and failures, that as a result the building has reach receiving the regular customers. With the assistance of this technique, the hotels these days are ready to strengthen the complete loyalty that has created and maintains strategic competitive advantage, For an example: we are able to contemplate IDS (intellectual information system) , A software package that is meant to boost the service of the building. This specific technology is incredibly a lot of useful in recording guest history.

Maintaining guest's personal records in these knowledgeable systems has enabled the building to spot the guest's needs and enquires like, varieties and figures of accommodation, span and time of keep individual necessities and plenty of additional. it's conjointly reach maintaining the repetitive visits and improve and increase the facilities and services by taking recommendation from its former shoppers.

These knowledgeable system or specialization system have helped within the advancement of caretaker services at the hotels, that provides info
24/7 days. the information gather in these systems have an excellent impact on selling ways likewise as facilitate to review sales and current trends of hotels trade. The distinguished ability of knowledgeable systems to assemble all the desired info and method it and conjointly to receive vital information has exaggerated the competitive advantage, the service provided and therefore the development of the employees performance in an exceedingly building.

Marketing ways are outlined by gathering info and it includes: making spam tenting, coming up with seasonal promotions, coming up with the time and placement of ad tenting, making customized advertising and shaping that market systems are growing speedily etc.

Though these AI roughly known as knowledgeable systems became masters of humans these days, one truth concerning welcome trade still remains a similar and can't get replaced ever. which is that the "human" issue, the service provided by one man to a different.

As per the oracle welcome report, space cleanliness continues to be important for in general guest fulfilment. we tend to tend to think about our age because the most innovative age of technology, tho' it's a real truth therefore for , these knowledgeable systems will solely facilitate within the space of operator if they're willing to take a position.

If considering the statistics thirty fifth of guests just like the ability of schedule space cleanup and twenty sixth likeable to receive a wise phone notification to point out if there room is being clean. It appears that technology is incredibly effective for serving guests. the simplest example for this can be japan. during this land of "Endless Discovery" (japan) robots in hotels don't seem to be simply novelties however a reality. The building "Henn na" opened in 2015 is recorded because the world's initial hotel served by robots. This development can have major social, economic and business effects.

According to Oracle welcome, the highest initiatives that a guest would love to ascertain in hotels includes: capability to pick specific space locations $(45 \%)$, means that to share info concerning in-destination activities (41\%), the checking check-out method (39\%), thanks to build service request $(36 \%)$. we are able to see a positive respond from the guest for the utilization of mobile application to act with hotels and 
employees and it includes: info and recommendation for visiting close places $(53 \%)$, providing further space amenities (47\%), and reservations for dialing in and out of the building (44\%).

During the shoppers keep within the building, the necessity for technology to be accessible within the space is high. The Wi-Fi uses are eighty two whereas thirty third are discontented with the service provided and sixty six need easier and quicker association. Customers are fascinated by technological devices to manage the sunshine and temperature within the space via a pill thirty second, a smartphone twenty seventh or a voice management twenty fifth. Nearly three out of four guests victimization space devices for amusement and twenty eighth confirms that technological innovations are a major a part of quality and repair provided by the building that ultimately adds to the expertise throughout a guest keep. concerning one quarter of guests have a regeneration towards the power to look at videos directly on their mobile devices.

Knowing the profile and therefore the behavior of the client helps to supply customized services, nevertheless personalization of welcome services are often through with the assistance of mobile technology even while not gathering an excessive amount of of knowledge concerning the shoppers. it's an evident truth after we say business customers prepare additional technologies to provide them higher services. The hoteliers has to invest additional in technological innovations and it includes: on-line checking and inspect, access to tourists info on native places of interest, attractions and events and employing a smartphone to unlock the sleeping room.

Such investments are notably necessary for business hotels since business shoppers appreciate their use of technological innovations over guests for leisure and vacation. The welcome service is improved once application of up to date technology is in a very position to provide extra freedom and probability to the consumer to manage the technological operations in accommodation: choosing the chamber, individual checking at arrival and individual examine at departures through mobile application, add functions for on-line checking and access to the chamber through contact free communication technologies etc.
The strategic goals for building operator's technology investments in a pair of 2017 have 2 clear priorities. which they are: over operators $(52 \%)$ are targeted on rising digital customers' engagement, and so the second priority is to incessantly concentrate on payment and data security (40\% Freed, 2017). the essential foundation of technological innovation in associate degree extremely building is to facilitate the work of the workers and so the keep of guest, to optimize the costs, and to impress customers with distinctive services and experiences beside emotions.

\section{Conclusion :}

The analysis has bought to thought, the influences of technological innovations in cordial reception service, that has determined on the premise of the guest cycle model. There are three major divisions of influences and effects and that they are: client behavior within the edifice service method, specific functions and tasks of the maintenance staff in providing edifice services, promoting methods and company policy, outlined by higher authorities of edifice firms beneath the impact of technological innovations. the current study portrays this researches and technological models concerning data technology that hotels have adopted. The results of this study shows the strategic management selections that are involved on the applying of technological innovation in edifice service. the connection between the cordial reception business and technology ought to be balanced and cordial further as harmonious. Technology has succeeded in adding worth, making amenities, personalizes the guest keep, however passing them will destroy the human relationships the guests are trying to find and appreciating. to make personalised guests experiences whereas respecting their privacy and finding the optimum mixture of digital and human interactions, became a contemporary day challenge to cordial reception and touristry business. Comfort and convincing the customer's satisfaction by value-added worth, investment in technology, ought to be fastidiously thought doubly before analyzed. Its realization ought to stimulate client loyalty and also the aggressiveness of the edifice firms. 


\section{Reference:}

[1] https://www.hoteliermagazine.com/housekeeping-isbeing-slowly-transformed-by-technology/

[2] https://www.todayshotelier.com/2018/03/13/nextlevel-housekeeping-via-technology/

[3] https://www.hospitalityupgrade.com/_magazine/Mag azineArticles/Housekeeping-Technology-CleaningUp.asp/

[4] https://phdessay.com/technology-and-how-it-hasimproved-housekeeping-operations/ 